\title{
GENERALIZED COMPOSITION OPERATOR FROM BLOCH-TYPE SPACES TO MIXED-NORM SPACE ON THE UNIT BALL
}

\section{Li ZHANG AND ZE-HuA ZHOU}

Abstract. Let $H(\mathbb{B})$ be the space of all holomorphic functions on the unit ball $\mathbb{B}$ in $\mathbb{C}^{N}$, and $S(\mathbb{B})$ the collection of all holomorphic self-maps of $\mathbb{B}$. Let $\varphi \in S(\mathbb{B})$ and $g \in H(\mathbb{B})$ with $g(0)=0$, the generalized composition operator is defined by

$$
C_{\varphi}^{g}(f)(z)=\int_{0}^{1} \Re f(\varphi(t z)) g(t z) \frac{d t}{t},
$$

Here, we characterize the boundedness and compactness of the generalized composition operator acting from Bloch-type spaces $\mathscr{B}_{\omega}$ and $\mathscr{B}_{\omega, 0}$ to mixed-norm space $H(p, q, \phi)$ on the unit ball $\mathbb{B}$.

Mathematics subject classification (2010): Primary: 47B38; secondary: 32A37, 32A38, 32H02, 47B33. Keywords and phrases: Generalized composition operator, Bloch-type spaces, mixed-norm spaces.

\section{REFERENCES}

[1] C. C. Cowen, B. D. MacCluer, Composition Operators on Spaces of Analytic Functions, CRC Press, Boca Raton, FL, 1995.

[2] D. D. Clahane, S. Stević, Norm equivalence and composition operators between Bloch/Lipschitz spaces of the unit ball, J. Inequal. Appl. Vol. 2006 (2006) 11. Article ID 61018.

[3] Z. Hu, Extended Cesàro operators on mixed norm spaces, Proc. Amer. Math. Soc. 131 (7) (2003) 2171-2179.

[4] S. Li, S. SteVić, Generalized composition operators on Zygmund spaces and Bloch type spaces, J. Math. Anal. Appl. 338 (2008) 1282-1295.

[5] S. Li, S. STEVIĆ, Products of composition and integral type operators from $H^{\infty}$ to the Bloch space, Complex Var. Elliptic Equ. 53 (2008) 463-474.

[6] S. Li, S. STEVić, Products of Volterra type operator and composition operator from $H^{\infty}$ and Bloch spaces to the Zygmund space, J. Math. Anal. Appl. 345 (2008) 40-52.

[7] S. Li, S. STEVić, Products of integral-type operators and composition operators between Bloch-type spaces, J. Math. Anal. Appl. 349 (2009) 596-610.

[8] S. Li, S. STEVIĆ, On an integral-type operator from iterated logarithmic Bloch spaces into Bloch-type spaces, Appl. Math. Comput. 215 (2009) 3106-3115.

[9] S. STEVIĆ, Generalized composition operators from logarithmic Bloch spaces to mixed-norm spaces, Util. Math. 77 (2008) 167-172.

[10] S. STEVIĆ, Generalized composition operators between mixed-norm and some weighted spaces, Numer. Funct. Anal. Optim. 29 (7-8) (2008) 959-978.

[11] S. STEVIĆ, On an integral operator from the Zymund space to the Bloch type space on the unit ball, Glasgow Math. J. 51 (2009) 275-287.

[12] S. STEVIĆ, Integral-type operators from a mixed-norm space to a Bloch-type space on the unit ball, Siberian J. Math. 50 (6) (2009) 1098-1105.

[13] S. S TEVIĆ, On a new integral-type operator from the Bloch space to Blochtype spaces on the unit ball, J. Math. Anal. Appl. 354 (2009) 426-434.

[14] S. STEVIĆ, On an integral-type operator from logarithmic Bloch-type spaces to mixed-norm spaces on the unit ball, Appl. Math. Comput. 215 (2010) 3817-3823. 
[15] S. STEVIĆ, On an integral operator between Bloch-type spaces on the unit ball, Bull. Sci. Math. 134 (2010) 329-339.

[16] S. STEVIĆ, On some integral-type operators between a general space and Bloch-type spaces, Appl. Math. Comput. 218 (2011) 2600-2618.

[17] S. STEVIĆ, Boundedness and compactness of an integral-type operator from Bloch-type spaces with normal weights to $F(p, q, s)$ space, Appl. Math. Comput. 218 (2012) 5414-5421.

[18] S. STEVIĆ, S. UeKI, Integral-type operators acting between weighted-type spaces on the unit ball, Appl. Math. Comput. 215 (2009) 2464-2471.

[19] S. STEVIĆ, S. UEKI, On an integral-type operator acting between Bloch-type spaces on the unit ball, Abstr. Appl. Anal. Vol. 2010 (2010) 14. Article ID 214762.

[20] A. Shields, D. WiLliams, Bounded projections, duality, and multipliers in spaces of analytic functions, Trans. Amer. Math. Soc. 162 (1971) 287-302.

[21] X. TANG, Extended Cesàro operators between Bloch-type spaces in the unit ball of $\mathbb{C}^{n}, \mathrm{~J}$. Math. Anal. Appl. 326 (2007) 1199-1211.

[22] W. F. YANG, X. G. MenG, Generalized composition operators from $F(p, q, s)$ spaces to Bloch-type spaces, Appl. Math. Comput. 217 (2010) 2513-2519.

[23] X. L. ZHU, Generalized composition operators and Volterra composition operators on Bloch spaces in the unit ball, Complex Var. Elliptic Equ. 54 (2) (2009) 95-102.

[24] X. L. ZHU, Generalized composition operators from generalized weighted Bergman spaces to Bloch type spaces, J. Korean Math. Soc. 46 (6) (2009) 1219-1232.

[25] X. L. ZHU, On an integral-type operator from Privalov spaces to Bloch-type spaces, Ann. Polon. Math. 101 (2) (2011) 139-147. 